\title{
A descriptive study on ESL learners' vocabulary knowledge through cognitive and metacognitive strategies
}

\author{
B R Aravind ${ }^{\mathrm{a}, 1, *}$, V Rajasekaran ${ }^{\mathrm{b}, 2}$ \\ ${ }^{\mathrm{a}, \mathrm{b}}$ School of Social Sciences and Languages (SSL),Vellore Institute of Technology, Chennai, Tamilnadu, India \\ ${ }^{1}$ aravind.abur@gmail.com*, ${ }^{2}$ rskaran2003@gmail.com \\ *Corresponding author
}

\section{ARTICLE INFO}

\section{Article history}

Received 10 July, 2020

Revised 12 August, 2020

Accepted 30 August, 2020

Keywords

Cognitive

Metacognitive

Vocabulary Learning Strategies

ESL learners

Teaching

\section{ABSTRACT}

The present research was carried out to study the cognitive and metacognitive vocabulary learning strategies of 36 ESL learners'. Schmitt's Vocabulary Learning Strategies questionnaire was used to conduct the study. The study revealed the subsequent array of cognitive and metacognitive strategies employed by ESL learners. Additionally, semi-structured interviews were also conducted with 10 ESL learners' who completed the questionnaire to get more reliable information about learners' strategies with vocabulary learning. The findings indicated that 'Using English Language Media', 'Verbal repetition', 'Take notes in class' were the most popular strategies, whereas 'Skip or pass new word' and 'Put English labels on physical objects' were least used. The results of this paper provide many implications for English language teaching. Detailed explanations of the participants' cognitive and metacognitive strategies were given in the discussion

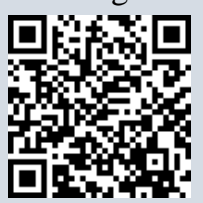

This is an open access article under the CC-BY-SA license.

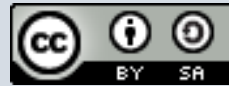

\section{Introduction}

"Without grammar, very little can be conveyed; without vocabulary, nothing can be conveyed" (Wilkins 1972, p. 111). Vocabulary learning starts at the very early stage of infancy. According to the National Research Council (1998), the foundations for language and literacy begin in early childhood when children develop vocabulary and use the vocabulary to communicate. 8 to 12 months; children understand 3 to 50 words. Those words were normally familiar persons in the family or their favorite objects around them. Even in a learner's mother tongue, there is incessant learning of new words and new meanings for old words (Thornbury 2002, p. 1). It is generally accepted that vocabulary is 'the heart in learning a second language', but the acquisition of numerous vocabulary items may be one of the most difficult aspects of learning a second language for most L2 learners (Meara 1980; Read 2000; Stoffer 1995).

Maley (1986) any learner of a foreign language knows very well that words are essential, and the lack of them leads to difficulties in communication situations. Decarrico (2001) points out that vocabulary learning is central to language acquisition whether it is a second or a foreign language. Vocabulary often seems to be the least systematized, and the least well-catered for of all the aspects of learning a foreign language, such as listening, speaking, reading, writing, grammar, or even pronunciation. Many scholars (e.g. Allen, 2009; Carter and McCarthy, 1988; Hughes, 1989; 2003; Jackson \& Amvela, 2007; Lewis, 1993; Long and Richards, 1997; Maley, 1986; Meara, 1980; 1982; Read, 2000; Richards, 1985; Schmitt, 1997; Seal, 1991; Zimmerman, 1996) specifically highlight the neglect of vocabulary studies. 


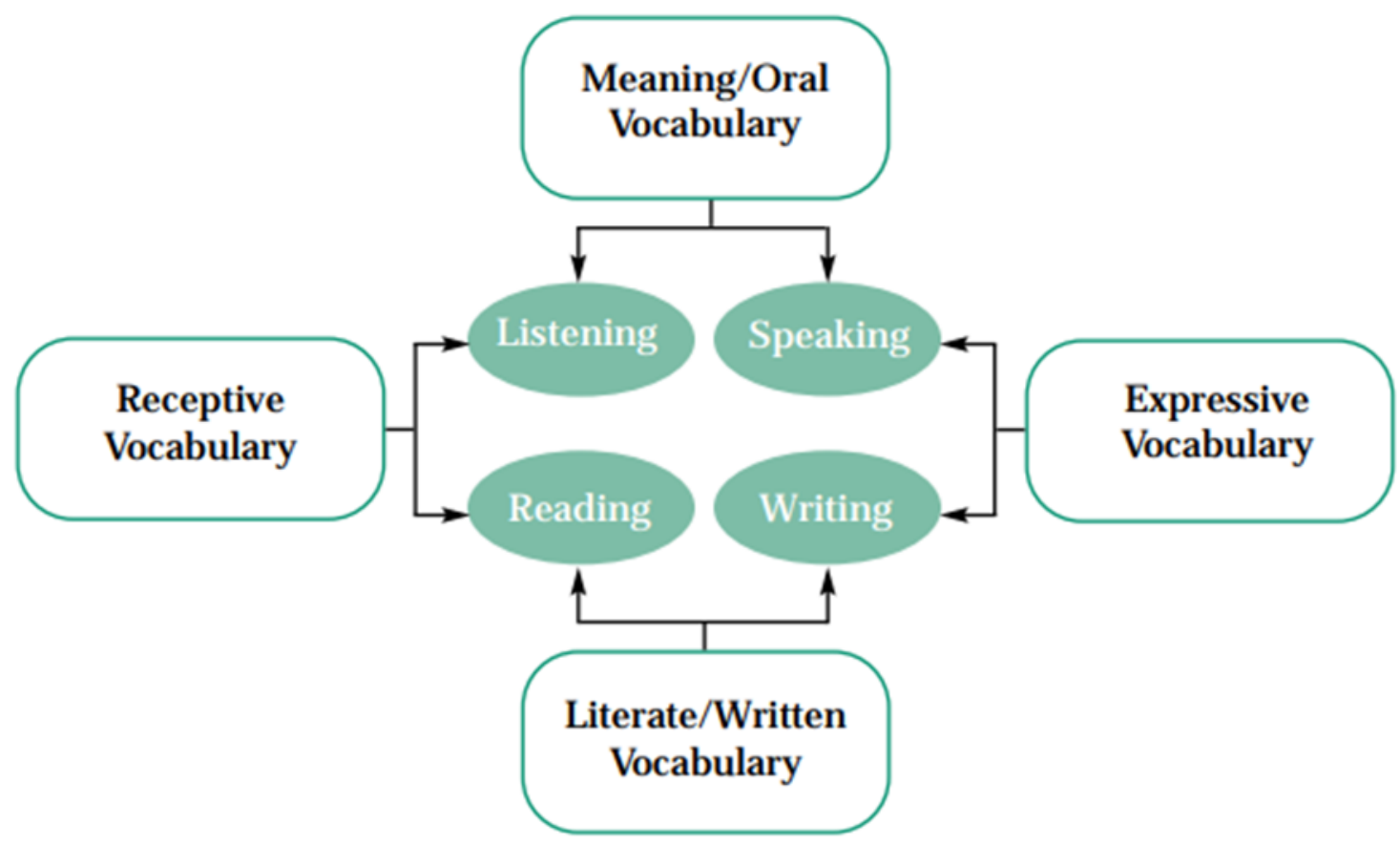

Fig. 1. Types of vocabulary (Source: Adapted from Pikulski and Templeton (2004, p. 2)

Pikulski and Templeton $(2004$, p. 2) demonstrate that vocabulary items play a dominant part in learning to communicate effectively while listening, speaking, reading, and writing. Vocabulary items in Fig. 1. can be classified in terms of types, meanings, and functions. Based on the diagram, vocabulary is categorized into four main groups as meaning/oral vocabulary, literate/written vocabulary, receptive vocabulary, and productive vocabulary. Hence, all vocabulary items are interrelated in functions and meanings. Vocabulary learning strategies are a part of language learning strategies which in turn are a part of general learning strategies (Nation 2001, p. 217). Cameron (2001, p. 92) defines vocabulary learning strategies as "the actions that learners take to help themselves understand and remember vocabulary items".

\subsection{Survey of literature}

Today, the significance of vocabulary is appreciated both in second language research and in language teaching. The number of studies and books concerning vocabulary instruction has increased. Thornbury (2002, p. 4) states, "This is partly due to the recent availability of computerized databases of words (or corpora), and partly due to the development of new approaches to language teaching which are much more word-centered, such as the lexical approach." Burns and Richards (2018) emphasized the importance of aptitude tests in Second Language Acquisition (SLA). Initial learning draws on conscious learning abilities, such as memory, reasoning, and analytic abilities assessed through aptitude tests in SLA. Mayer (2019) mentioned the influence of multimedia in learners' deep learning. The impact of deep learning was more from words and pictures than from words alone.

Amirian and Heshmatifar (2013) conducted a study on "A Survey on Vocabulary Learning Strategies: A Case of Iranian EFL University Students". 74 students were used for the study. The result showed that determination strategies were frequently used by the students. Guessing from context and dictionary usage are the most popular strategies for the Iranian learners to acquire vocabulary.

Ramos (2015) reviewed incidental vocabulary learning under the title, "Incidental Vocabulary Learning in Second Language Acquisition: A Literature Review". In the article, he surveyed the understanding of incidental learning and the relationship of reading and the promotion of vocabulary learning through strategies and tasks with technology-based methods.

Rabadi (2016) investigated a study on "Vocabulary Learning Strategies Employed by Undergraduate EFL Jordanian Students". 110 students were used for the study. The study showed 
that memory strategies were the most frequently employed by them and metacognitive strategies were the least frequently used strategies among them. In addition, the study revealed that the variation of Jordanian participants' choice of vocabulary learning strategies were medium strategy users.

Nosratinia et al., (2017) published a research paper on "Promoting Second Language Learners' Vocabulary Learning Strategies: Can Autonomy and Critical Thinking Make a Contribution?" 100 undergraduate EFL learners were used for the study. Three questionnaires were given to estimate their critical thinking, autonomy and vocabulary learning strategies, and analyzed by Pearson's product-moment correlation coefficient. Findings showed the significant relationships between autonomy and critical thinking, critical thinking and vocabulary learning strategies, autonomy and vocabulary learning strategies. In addition, the stepwise method revealed autonomy is the best predictor of vocabulary learning strategies. Specifically, EFL learners' autonomy predicts 20 percent of vocabulary learning strategies compared to critical thinking.

Aravind and Rajasekaran (2018) conducted a study on strategies used by research scholars in vocabulary learning. The findings revealed that the frequent strategies employed were using new words in the sentence, note-taking in the class, studying or spelling of words, spoken repetition, and usage of dictionary. Other strategies like the Peg method, analyzing of parts of speech, flashcards were not preferred by the research scholars in vocabulary learning.

\subsection{Schmitt's vocabulary learning strategies}

Strategies in vocabulary learning were intended to retrieve the learned vocabulary in language learning. Schmitt's Taxonomy of Vocabulary Learning Strategies (1997) was based on Oxford's (1990) social, memory, cognitive, and metacognitive categories. Schmitt classifies vocabulary learning strategies into two divisions namely discovery strategies and consolidation strategies. The current study investigates cognitive and metacognitive strategies of ESL learners' which comes under consolidation strategies of Schmitt's taxonomy of vocabulary learning strategies. Cognitive strategies include mechanical means of learning vocabulary. Metacognitive strategies used by learners to manage and assess their individual learning process in vocabulary.

\subsection{Research objectives}

There are three research objectives. They are to study the cognitive and metacognitive strategies used by ESL learners' for their vocabulary development, to find out the most and least frequently used cognitive and metacognitive strategies among ESL learners, and to determine which of these strategies are more reported by ESL learners' during semi-structured interview.

\subsection{Research questions}

The research questions are formulated in three questions. What are the effective cognitive and metacognitive strategies to enrich the vocabulary level of ESL learners'? Do cognitive and metacognitive strategies motivate ESL learners' in vocabulary enhancement? What are the most and least frequently cognitive and metacognitive strategies used by ESL learners?

\subsection{Significance of the study}

Vocabulary learning strategies play a major part in assisting ESL learners to acquire and learn new words easily. Studies proved that learners have their own strategies to promote and uplift their vocabulary knowledge. The current study can be beneficial in promoting and assisting ESL learners to direct effective strategies to learn vocabulary in English. ESL educators and practitioners can enhance the teaching-learning process by exposing the number of strategies employed by other ESL learners around the world. Also, they can instruct cognitive and metacognitive strategies that facilitate ESL learners' vocabulary development. The findings of this investigation can be an information base for further research in the related field.

\section{Research Method}

The research methodology employed in this study was a mixed research methodology. Schmitt's Vocabulary Learning Strategies Questionnaire was adopted to study the participants' vocabulary knowledge. Especially cognitive and metacognitive strategies were used from Schmitt's Vocabulary Learning Strategies Questionnaire to investigate the effectiveness and the impact of 36 ESL 
learners' vocabulary knowledge. All the 14 items in the questionnaire $(9$ cognitive and 5 metacognitive) were collected through online source of Google Forms 2020 as shown in Table 1. The rating scale for the frequency of use of the cognitive and metacognitive strategies as Helpful, Not Helpful, Not Used but Helpful, and Not Aware. Additionally, semi-structured interviews were also conducted with 10 ESL learners' who completed the questionnaire to get more reliable information about learners' strategies with vocabulary learning.

Table 1. Classification of the items in the questionnaire

\begin{tabular}{cc}
\hline Items & Cognitive Strategies \\
\hline 1 & Verbal repetition \\
2 & Written repetition \\
3 & Wordlists \\
4 & Prepare flashcards \\
5 & Take notes in class \\
6 & Use vocabulary section in text book \\
7 & Listen to tape of new words \\
8 & Put English labels on physical objects \\
9 & Keep vocabulary notebook \\
\hline Items & Metacognitive Strategies \\
\hline 10 & Use English language media (songs, newspaper/newscasts etc.,) \\
11 & Testing oneself with word tests \\
12 & Use spaced word practice \\
13 & Skip or pass new word \\
14 & Continue to study over time \\
\hline
\end{tabular}

The present study was conducted with 36 third-year ESL learners who were randomly selected on single-stage cluster sampling. The participants comprised 20 male and 16 female participants ranging from 18 to 19 years old (see Table 2). The sample's proficiency level ranges between intermediate low and intermediate high. Participant's demographical details, length of time studying English, and other background information were also collected from the participants' responses. All the participants were exposed to the uniform treatment conditions for the study although they had various language backgrounds.

Table 2.

Description of samples

\begin{tabular}{cc}
\hline Category & Number \\
\hline Male & 20 \\
Female & 16 \\
Total & 36 \\
\hline
\end{tabular}

\section{Findings and Discussion}

The result of ESL learners' use of cognitive strategies presented in Table. 3. The statistical details includes participants' average, standard deviation and median scores from Schmitt's Vocabulary Learning Strategies Questionnaire. 
Table 3. Statistical details of ESL learners' cognitive strategies

\begin{tabular}{ccccc}
\hline Cognitive Strategies & Helpful & Not Helpful & Not Used but Helpful & Not Aware \\
\hline Verbal repetition & $32(88.9 \%)$ & $4(11.1 \%)$ & 0 & 0 \\
Written repetition & $30(83.3 \%)$ & $3(8.3 \%)$ & $3(8.3 \%)$ & 0 \\
Wordlists & $31(86.1 \%)$ & $3(8.3 \%)$ & $2(5.6 \%)$ & 0 \\
Prepare flashcards & $21(58.3 \%)$ & $4(11.1 \%)$ & $5(13.9 \%)$ & $6(16.7 \%)$ \\
Take notes in class & $32(88.9 \%)$ & $3(8.3 \%)$ & $1(2.8 \%)$ & 0 \\
Use vocabulary section in text book & $28(77.8 \%)$ & $3(8.3 \%)$ & $4(11.1 \%)$ & $1(2.8 \%)$ \\
Listen to tape of new words & $28(77.8 \%)$ & $1(2.8 \%)$ & $4(11.1 \%)$ & $3(8.3 \%)$ \\
Put English labels on physical objects & $19(52.8 \%)$ & $3(8.3 \%)$ & $7(19.4 \%)$ & $7(19.4 \%)$ \\
Keep vocabulary notebook & $20(55.6 \%)$ & $5(13.9 \%)$ & $6(16.7 \%)$ & $5(13.9 \%)$ \\
Average & 26.7 & 3.2 & 3.5 & 2.4 \\
Standard Deviation & 5.3 & 1.0 & 2.2 & 2.8 \\
Median & 28 & 3 & 4 & 1 \\
\hline
\end{tabular}

Table 3 shows the average, standard deviation, and median value of the 9 cognitive strategies. The total group mean of the study is 26.7. The standard deviation of the cognitive strategies is 5.3. The median value of cognitive strategies is 28 as shown in Table 3.

Table 4. Statistical details of ESL learners' metacognitive strategies

\begin{tabular}{ccccc}
\hline Metacognitive Strategies & Helpful & Not Helpful & Not Used but Helpful & Not Aware \\
\hline Use English Language Media & $33(91.7 \%)$ & $2(5.6 \%)$ & 0 & $1(2.8 \%)$ \\
(Songs/newspaper/newscasts etc.) & $30(83.3 \%)$ & $1(2.8 \%)$ & $5(13.9 \%)$ & 0 \\
Testing oneself with word tests & $23(63.9 \%)$ & $2(5.6 \%)$ & $4(11.1 \%)$ & $7(19.4 \%)$ \\
Use spaced word practice & $13(36.1 \%)$ & $14(38.9 \%)$ & $2(5.6 \%)$ & $7(19.4 \%)$ \\
Skip or pass new word & $23(63.9 \%)$ & $9(25 \%)$ & $2(5.6 \%)$ & $2(5.6 \%)$ \\
Continue to study over time & 24.4 & 5.6 & 2.6 & 3.4 \\
Average & 7.7 & 5.6 & 1.9 & 3.3 \\
Standard Deviation & 23 & 2 & 2 & 2 \\
Median & &
\end{tabular}

Table 4 shows the average, standard deviation, and the median value of the 5 metacognitive strategies. The total group mean of the study is 24.4. The standard deviation of the metacognitive strategies is 7.7. The median value of metacognitive strategies is 23 as shown in Table 4. 


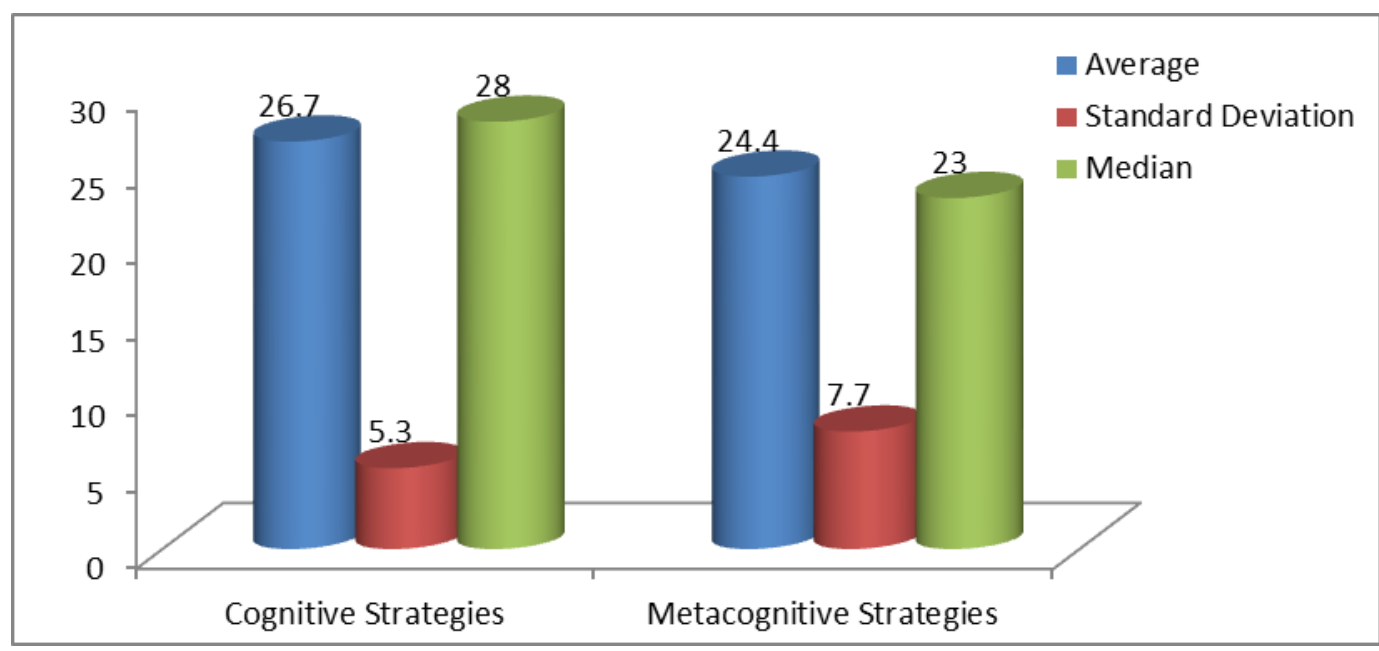

Fig. 2. Graphical representation of the comparison of cognitive and metacognitive strategies

Table 5. Most frequently used cognitive and metacognitive strategies of ESL learners'

\begin{tabular}{ccc}
\hline Strategies & Category & Respondents \\
\hline Use English Language Media & Metacognitive & $33(91.7 \%)$ \\
(Songs/newspaper/newscasts etc.) & Cognitive & $32(88.9 \%)$ \\
Verbal repetition & Cognitive & $32(88.9 \%)$ \\
Take notes in class & Cognitive & $31(86.1 \%)$ \\
Wordlists & Metacognitive & $30(83.3 \%)$ \\
Testing oneself with word tests & Cognitive & $30(83.3 \%)$ \\
Written repetition & & \\
\hline
\end{tabular}

Table 6. Least frequently used cognitive and metacognitive strategies of ESL learners'

\begin{tabular}{ccc}
\hline Strategies & Category & Respondents \\
\hline Skip or pass new word & Metacognitive & $13(36.1 \%)$ \\
Put English labels on physical objects & Cognitive & $19(52.8 \%)$ \\
Keep vocabulary notebook & Cognitive & $20(55.6 \%)$ \\
Prepare flashcards & Cognitive & $21(58.3 \%)$ \\
\hline
\end{tabular}

From the responses of the ESL learners', all the cognitive and metacognitive strategies were put together to find the most and least frequently used strategies were reported as shown in Table 5 and Table 6. Based on ESL learners' responses to the 'Helpful' population, the most and least strategies were calculated. ESL learners' most frequently used strategies were 'Use English Language Media' with $33(91.7 \%)$ from metacognitive strategies, 'Verbal repetition' with $32(88.9 \%)$, 'Take notes in class' with 32 (88.9\%), 'Wordlists' with 31 (86.1\%) from cognitive strategies, 'Testing oneself with word tests' with $30(83.3 \%)$ from metacognitive strategies and 'Written repetition' with 30 (83.3\%) from cognitive strategies were reported by the ESL learners. On the other hand, least frequently used strategies by ESL learners are 'Skip or pass new word' with 13 (36.1\%) from metacognitive strategies, 'Put English labels on physical objects' with 19 (52.8\%), 'Keep vocabulary notebook' with 20 (55.6\%), and 'Prepare flashcard' with $21(58.3 \%)$ from cognitive strategies were reported by the learners for vocabulary learning.

ESL learners use these cognitive strategies to consolidate new words in vocabulary learning from the perspective of mental process. $32(88.9 \%)$ participants answered the strategies 'Take notes in 
class' and 'Verbal repetition' of the dictions to register the words in mind and these two strategies reported the most highly used cognitive strategies. 'Take notes in class' strategy is though found classical, learners believed this strategy to consolidate the words till date for the learning process. 'Verbal repetition' is to register the word in the mental process of learning, where the learners' alleged articulation in the cognitive domain is possible in remembering the word to learn. 19 $(52.8 \%)$ ESL learners' said that 'Put English labels on physical objects' as least used strategy in learning the vocabulary. Hence, it cannot be taken lightly into the consideration of consolidating the vocabulary in cognitive strategies.

Learners use metacognitive strategies to deepen the thinking-learning process in vocabulary from the perspective of advanced cognitive levels. 33 (91.7\%) learners responded that 'Use English Language Media' as a highly used strategy in order to plan and decide the word for manipulation. Moreover, this strategy had scored most of the participants' responses in the metacognitive strategies list. Because ESL learners believe Newspaper, songs, videos give a new angle in remembering the words; they find it novel for learning the vocabulary. Surprisingly $13(36.1 \%)$ learners were on the view that it was helpful to 'Skip or pass the new word' in the learning process and it has ranked the least used strategy in the metacognitive list. At the same time, 14 (38.9\%) participants strongly disagree with skipping the new word and it was not helpful in vocabulary learning. As an ESL learner, mastery of vocabulary is very much essential in the productive work; words cannot be skipped or passed without learning in the educational progression.

\section{Reported Strategies by ESL Learners'}
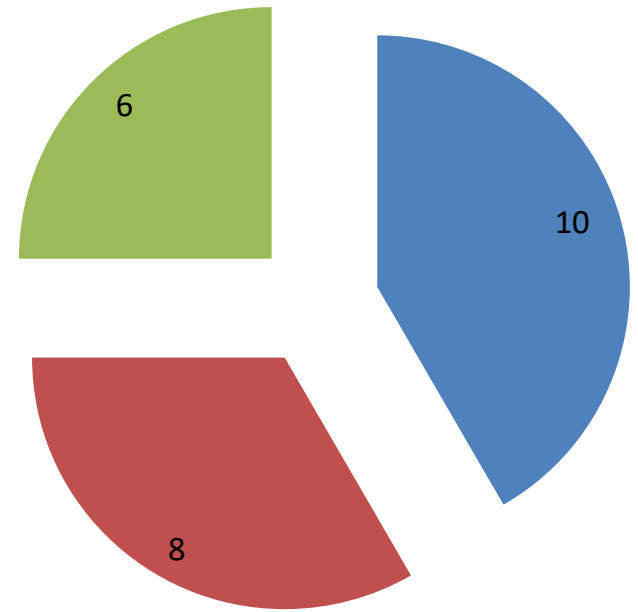

- Use English Langauge Media

- Take notes in class

Verbal repetition

Fig. 3.

Reported strategies by ESL learners' for vocabulary learning

In order to ascertain the responses of ESL learners' attitudes about cognitive and metacognitive strategies, randomly 10 learners were selected and questioned in the form of semi-structured interviews. The learners' responses were projected in Fig. 3. The questions posed to learners as follows. The first question, what is the most frequently used strategy for you, and why? All the 10 participants responded 'Use English Language Media' as the most frequently used strategy according to them. They said this particular strategy deepens the understanding level and fasten the learning process. It reported the high number of participants in both cognitive and metacognitive strategies. The second question is named a strategy that is useful in the class. 8 respondents replied 'Take notes in class' as the useful strategy in the class. During the lectures, learners find this strategy as a powerful strategy since they themselves write the words when they encounter it. The final question to the interviewees is which strategy helps you to remember the word? 6 interviewees said the 'Verbal repetition' strategy assist them to remember the learned word. Learners keep repeating the words again and again to remember the word. All those 3 interview questions were posed to the participants to name a particular strategy from the cognitive and metacognitive strategies. The 
participants' opinions were collected and distributed on the bases of responses to the questions. Based on the interview report, 'Use English Language Media', 'Take notes in class', and 'Verbal repetition' are the cognitive and metacognitive strategies reported by ESL learners during the semistructured interviews for vocabulary learning and development.

\section{Conclusion}

The prime focus of this research is to study the cognitive and metacognitive strategies on ESL learners' vocabulary learning. It also sought to find out ESL learners' most and least used strategies. The finding of the study revealed the reliability of the research from the questionnaire and interview responses of the participants. Data analysis indicated that reported and responded strategy use increased learners' perceptions towards cognitive and metacognitive strategies on vocabulary. Based on the findings of the study, 'Use English Language Media', 'Take notes in class' strategies should be considered to be included in the vocabulary teaching-learning process of ESL learners. Since both instructors and the learners were in favor of the strategy training in language learning. To conclude, this study reveals that strategies in learning vocabulary may help the learner to discover themselves and it pave way for them into independent learners. The flexibility shown by the ESL learners towards being independent is significant in 'Written repetition' and 'Verbal repetition' strategies. It indicates that when guided with proper context, they can be more autonomy in learning and developing vocabulary effectively. The least used strategies of this study could help the practitioners to enhance the teaching strategies in vocabulary and also they could introduce the vocabulary learning strategies in the teaching-learning process.

\section{References}

Allen, V. F. (2009). Techniques in teaching vocabulary. New York: Oxford University Press.

Amirian, S. M. R., \& Heshmatifar, Z. (2013). A survey on vocabulary learning strategies: A case of Iranian EFL university students. Journal of Language Teaching and Research, 4(3), 636. https://doi:10.4304/jltr.4.3.636-641

Aravind, B. R., \& Rajasekaran, V. (2018). A study on vocabulary learning strategies research scholars. The International Journal of Research in Teacher Education, 9, 16-25. http://ijrte.penpublishing.net/makale/493

Burns, A., \& Richards, J. C. (2018). The Cambridge guide to learning English as a second language. Cambridge, United Kingdom: Cambridge University Press.

Cameron, L. (2001). Teaching languages to young learners. Cambridge: Cambridge University Press.

Carter, R., McCarthy, M., Channell, J., \& McCarthy, M. (1988). Vocabulary and language teaching (pp. 6875). London: Longman.

Decarrico, J. S. (2001). Vocabulary learning and teaching. In M. Celce-Murcia (Ed.), Teaching English as a second or foreign language (3rd ed.) (pp. 285-299). Boston: Heinle \& Heinle.

Hughes, A. (1989). Testing for language teachers. Cambridge: Cambridge University Press.

Hughes, A. (2003). Testing for language teachers. Cambridge: Cambridge University Press.

Jackson, H., and Amvela, E. Z. (2007). Words, meaning and vocabulary: An introduction to modern English lexicology. Bloomsburry Publishing.

Lewis, M. (1993). The lexical approach (Vol. 1). Hove: Language Teaching Publications.

Long, M. H., and Richards, J. C. (1997) Series editors' preface. In J. Coady and T. Huckin (Eds.), Second language vocabulary acquisition: A rationale for pedagogy (pp. ix-x). Cambridge: Cambridge University Press.

Maley, A. (1986). Series editors' preface. In J. Morgan, and M. Rinvolucri (Eds.), Vocabulary. Oxford: Oxford University Press.

Mayer, R. E. (2019). The Cambridge handbook of multimedia learning. Cambridge: Cambridge University Press. 
Meara, P. (1980). 'Vocabulary acquisition: A neglected aspect of language learning'. Language Teaching and Linguistics, 13 (4): 221-246. https://doi:10.1017/s0261444800008879

Meara, P. (1982). Vocabulary acquisition: A neglected aspect of language learning. In V. Kinsella (Ed.), Surveys: eight state-of-the-art article on key areas in language teaching (pp. 100-126). Cambridge: Cambridge University Press.

Nation, P. (2001). Learning vocabulary in another language. Cambridge: Cambridge University Press.

Nosratinia, M., \& Zaker, A. (2017). Scrutinizing the impact of teachers' critical thinking and teaching autonomy on their teaching success and learners' use of language learning strategies. Journal of Language Teaching and Research, 8(1), 122-132. https://doi:10.17507/jltr.0801.15

Oxford, R. (1990). Language learning strategies: What every teacher should know. Boston: Heinle \& Heinle Publishers.

Pikulski, J. J., and Templeton, S. (2004). Teaching and developing vocabulary: Key to long-term reading success. Current research in reading/language arts, 1, 12 . Available: http://www.eduplace.com/state/pdf/author/pik_temp.pdf

Rabadi, R. I. (2016). 'Vocabulary learning strategies employed by undergraduate EFL Jordanian students'. English Language and Literature Studies, 6(1), 47. https://doi:10.5539/ells.v6n1p47

Ramos, F. D. (2015). 'Incidental vocabulary learning in second language acquisition: A literature review'. PROFILE Issues in Teachers Professional Development, 17(1), 157-166. https://doi:10.15446/profile.v17n1.43957

Read, J. (2000). Assessing vocabulary. Cambridge: Cambridge University Press.

Richards, J. C. (1985). The context of language teaching. Cambridge: Cambridge University Press.

Schmitt, N. (1997). Vocabulary learning strategies. In N. Schmitt and M. McCarthy (Eds.), Vocabulary: Description, acquisition and pedagogy (pp. 77-85). Cambridge: Cambridge University Press.

Seal, B. D. (1991). Vocabulary learning and teaching. In M. Celce-Murcia, (Ed.), Teaching English as a second or foreign language (pp. 296-311). Massachusetts: Heinle \& Heinle.

Stoffer, I. (1995). University foreign language students' choice of vocabulary learning strategies as related to individual difference variables. Unpublished Doctoral Dissertation, the University of Alabama, USA.

Thornbury, S. (2002). How to teach vocabulary. Harlow: Longman-Pearson Educational.

Wilkins, D. A. (1972). Linguistics in language teaching, Edward Arnold, London. US Department of Education.

Zimmerman, C. (1996). Historical trends in second language vocabulary instruction. In J. Coady \& T. Huckin (Eds.), Second language vocabulary acquisition: A rationale for pedagogy (Cambridge Applied Linguistics, pp. 5-19). Cambridge: Cambridge University Press. https://doi:10.1017/CBO9781139524643.003 